\title{
Deoxynivalenol Biosynthesis-Related Gene Expression During Wheat Kernel Colonization by Fusarium graminearum
}

\author{
Heather E. Hallen-Adams, Nancy Wenner, Gretchen A. Kuldau, and Frances Trail
}

First and fourth authors: Department of Plant Biology, Michigan State University, East Lansing; second and third authors: Department of Plant Pathology, Penn State University, State College; and fourth author: Department of Plant Pathology, Michigan State University, East Lansing.

Current address of H. E. Hallen-Adams: Department of Food Science and Technology, University of Nebraska, Lincoln. Accepted for publication 20 April 2011.

\begin{abstract}
Hallen-Adams, H. E., Wenner, N., Kuldau, G. A., and Trail, F. 2011. Deoxynivalenol biosynthesis-related gene expression during wheat kernel colonization by Fusarium graminearum. Phytopathology 101:1091-1096.

Deoxynivalenol (DON) is a potent mycotoxin and virulence factor produced by Fusarium graminearum. We examined the expression of the core DON biosynthetic gene Tri5 during wheat head infection of susceptible and resistant cultivars and susceptible cultivars treated with strobilurin fungicides (e.g., azoxystrobin). DON was quantified to correlate expression with toxin accumulation. The highest Tri5 expression relative to housekeeping genes occurred at the infection front. As infection progressed, earliest-infected kernels showed diminished relative Tri5 expression but Tri5 expression never ceased during the 21 days

observed. Azoxystrobin treatment showed no significant effect on either relative Tri5 expression or DON quantity. The resistant cultivar 'Alsen' showed minimal spread of the fungus, with no fungus detected by day 21 . DON was not detected in significant quantities in Alsen in the later stages sampled. In Wheaten, DON levels were negligible at 8 days postinoculation (dpi), with detectable DON at later-sampled time points. Tri5 was detected even in fully senesced kernels 21 dpi. Our data demonstrate the presence of Tri5 transcripts in a susceptible cultivar over a much longer time period than has been previously documented. This suggests the ability of the fungus to rapidly resume toxin biosynthesis in dried infected grain should conducive environmental conditions be present, and provides a possible mechanism for high DON levels in asymptomatic grain.
\end{abstract}

Fusarium graminearum Schwabe (teleomorph Gibberella zeae (Schwein.) Petch) is a devastating pathogen of small grains, causing head blight and crown rot of wheat and barley and ear rot and stalk rot of maize, as well as opportunistically infecting other cereal crops (rice, oat, rye, etc.) (42). In addition to loss of crop productivity and biomass, $F$. graminearum produces several mycotoxins that render harvested grain unfit for consumption; notably, the trichothecene mycotoxins deoxynivalenol (DON) and its acetylated derivatives (3ADON and 15ADON), nivalenol (NIV); and the estrogenic polyketide zearalenone $(9,11)$.

The DON biosynthetic pathway is well characterized $(9,37)$. In $F$. graminearum, 12 biosynthetic genes are found in a core cluster on chromosome 2, with three additional genes (Tri1, Tri101, and Tri15) located elsewhere (chromosomes 1, 4, and 3, respectively) (28). The sequenced strain of $F$. graminearum, PH-1, lacks functional Tril3 and Tri7, leading to the production of DON and the concomitant inability to produce NIV $(20,29)$. Tri5, encoded by a core cluster gene, catalyzes the formation of trichodiene from farnesyl pyrophosphate, the first step in trichothecene biosynthesis. Consequently, Tri5 is an attractive target for mutagenesis $(2,36)$ and for molecular detection of trichothecene-producing Fusarium spp. $(22,34,38,44,47)$. Several studies have focused on Tri5 expression to unravel specific aspects of the $F$. graminearum-host interaction. Stephens and colleagues (41) used Affymetrix GeneChips to examine Fusarium gene expression during crown rot of wheat, and reported significant upregulation of Tri5 and Tri14 in planta (compared with mycelial culture). Zhang and colleagues (48) compared Tri5 expression between

Corresponding author: F. Trial; E-mail address: trail@msu.edu

doi:10.1094/PHYTO-01-11-0023

(c) 2011 The American Phytopathological Society carbendazin-resistant and -sensitive $F$. graminearum in shake culture and found higher expression levels in the resistant strain. Gardiner et al. (14) showed that Tri5 is strongly expressed in the rachis tissue of wheat, implicating DON in the early spread through the head. Early biosynthesis of wheat polyamines during infection suggests that these host compounds are important inducers of DON (13).

DON is produced primarily during plant infection, although DON production can be induced in vitro under special conditions (31). An infection time course in barley using the Fusarium GeneChip identifies DON biosynthetic genes among those uniquely expressed in planta (compared with genes expressed during growth in complete and carbon- and nitrogen-starved media) (20). DON and NIV are the only mycotoxins known to act as virulence factors and, in wheat, have been shown to be essential for virulence in head blight $(2,10,36)$ but not for crown rot (33). Furthermore, DON has been shown to be essential for the spread of $F$. graminearum from floret to rachis in wheat by preventing host cell wall reinforcement (26). However, the same study showed limited spread of $F$. graminearum in barley, with or without DON production (26). DON production has not been demonstrated in rice (16), and DON is produced but not essential for infection in maize $(1,36)$. In another study, DON-deficient mutants were unable to spread beyond the inoculated spikelet in wheat but did not differ significantly from the wild type in their ability to cause disease in rice and barley (30).

Previous studies have reported an increase in DON production in wheat treated with strobilurin fungicides such as azoxystrobin $(5,47)$. Another study $(35)$ reported increased DON in wheat plots treated with azoxystrobin alone or in combination with triazoles as opposed to plots treated with triazoles alone. Additionally, strobilurins are known to delay plant senescence (3). If expression of DON biosynthetic genes is associated with green tissue and 
tissue remains green longer, then the appearance of higher levels of DON in strobilurin-treated wheat could be explained by the delayed senescence. Here, we tested whether higher levels of DON are found in strobilurin-treated wheat, and whether DON biosynthetic genes are mainly expressed in green tissue.

In this study, we used Fusarium Affymetrix GeneChip data to build a profile of DON biosynthetic gene expression during wheat infection. We then used quantitative reverse transcript polymerase chain reaction (qRT-PCR) to evaluate the expression of Tri5, the first committed step in DON production, during an infection time course, collecting data day by day and kernel by kernel in 'Wheaten', a susceptible cultivar of spring wheat. A relevant subset of time points was additionally examined in Wheaten treated with azoxystrobin, and in the resistant cultivar 'Alsen'. Alsen possesses the quantitative trait locus FHB1, which is associated with resistance to Fusarium head blight and, specifically, to the effects of DON (45). Furthermore, representative kernels were sampled to evaluate the relationship between Tri5 expression levels and DON quantity. We found that transcription of DON biosynthetic genes in the fungus was initiated within $24 \mathrm{~h}$ of infection and did not cease throughout the time points examined. Furthermore, resistant Alsen appeared to be able to eliminate the fungus over time. Our findings suggest a possible mechanism for high DON levels in asymptomatic grain.

\section{MATERIALS AND METHODS}

Fungal strains and growth conditions. The strain of F. graminearum used for this study, Michigan field isolate PH-1 (FGSC 9075; NRRL 31084) (43), has had its genome sequenced (7). The genome sequence and annotation are publicly available (http:// www.broad.mit.edu/annotation/genome/fusarium_graminearum/ MultiHome.html; http://mips.gsf.de/genre/proj/FGDB). F. graminearum was maintained as mycelia and conidia $\left(5 \times 10^{5}\right.$ conidia $\mathrm{ml}^{-1}$ ) in $35 \%$ glycerol at $-80^{\circ} \mathrm{C}$ and on sterile soil at $-20^{\circ} \mathrm{C}$.

Wheat cultivars and inoculation of plants. Seed of spring wheat (Triticum aestivum L.) Wheaten and Alsen were planted in 9-cm clay pots ( 4 seeds per pot) and maintained in the greenhouse at $\approx 24^{\circ} \mathrm{C}$ with supplemental lighting. Wheat and kernel developmental stages were characterized using the Zadoks two-digit scale (46). Plants were inoculated 2 to 3 days after heading (prior

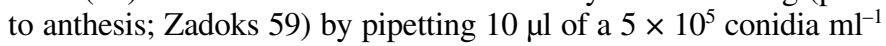
suspension into a spikelet at the midpoint of the rachis, as in Guenther and Trail (19). One plant per pot was mock inoculated with $35 \%$ glycerol. Plants were then placed in a mist chamber in the greenhouse at $24^{\circ} \mathrm{C}$ for 3 days before being returned to the greenhouse bench.

Harvest. Beginning 6 days postinoculation (dpi), kernels from susceptible Wheaten were collected, progressing outward from the inoculation point (IP). The rachis node immediately above the IP was designated +1 , the node above that +2 , and so on, while nodes descending from the IP were designated $-1,-2,-3$, and so on. All kernels from a given position (e.g., +1) from 12 plants were pooled, flash frozen in a dry ice/ethanol bath, lyophilized, and stored at $-80^{\circ} \mathrm{C}$ until RNA isolation. Collection continued daily through $14 \mathrm{dpi}$. At harvest, presence or absence of visible infection of the kernels and of the awns were noted. Kernels from resistant Alsen were harvested at 8,11, 14, 17, and $21 \mathrm{dpi}$; for the 17- and 21-dpi plants, the first and second centimeter of stem below the head were also separately harvested.

Fungicide treatment. Spring wheat Wheaten was grown and inoculated as above. The wheat was treated with the azoxystrobin fungicide Quadris (Syngenta, Greensboro, NC) at boot (Zadoks 45) and again immediately following removal from the mist chamber (Zadoks 65). A second set of plants was inoculated simultaneously as an untreated control. Kernels from treated and untreated plants were harvested at 8,11, 14, 17, and $21 \mathrm{dpi}$; for the 17- and 21-dpi plants, the first and second centimeter of stem below the head were also separately harvested. Although we followed the manufacturer's guidelines for application of the fungicide to wheat, it should be noted that Quadris is not approved for treatment of Fusarium head blight.

RNA extraction. RNA extraction utilized the lithium chloridebased method described by Goswami et al. (17). Following ethanol precipitation, $100 \mu \mathrm{g}$ of RNA was brought to $88 \mu \mathrm{l}$ in RNase-free water and treated with DNase I (Roche, Basel, Switzerland) for $15 \mathrm{~min}$ at $37^{\circ} \mathrm{C}$. The sample was then purified with an RNeasy Mini Kit (Qiagen, Hilden, Germany) following the manufacturer's instructions.

qRT-PCR. RNA ( $3 \mu \mathrm{g}$ ) was used in a $20-\mu$ l first-strand cDNA synthesis reaction using an AffinityScript QPCR cDNA Synthesis Kit (Agilent, Santa Clara, CA) following the manufacturer's instructions. For each template, a control reaction was also run without reverse transcriptase. The following primers were designed to amplify from the trichodiene synthase gene (Tri5; FGSG_03537), a necessary component of the DON pathway, the housekeeping genes for glyceraldehyde 3-phosphate dehydrogenase (GAPDH; FGSG_16627) and translation elongation factor $1 \propto(E F 1 A ;$ FGSG_08811) from $F$. graminearum, and the housekeeping gene for actin from wheat (AY663392.1): Tri5 F, TCTATGGCCCAAGGACCTGTTTGA and Tri5 R, TGACCC AAACCATCCAGTTCTCCA; GAPDH F, CTACATGCTCAAG TACGACTCTTCC and GAPDH R, GCCGGTCTCGGACCA CTTG; EFIA F, AAAGACCCTCCTTGAGGCCATTGA and EF1A R, ACTTCAGTGGTGACGTTGGAAGGA; and wheat ACT1 F, ACGTGGATATCAGGAAGG and wheat ACT1 R, ACATCTGTTGGAAAAGTGC. Optimal primer concentrations were determined empirically, with Tri5 and GAPDH reactions using 1 pmol each primer, while EFIA and ACT reactions used 10 pmol. Reactions $(25 \mu \mathrm{l}$ total) were prepared using Brilliant II SYBR Green QPCR Master Mix (Agilent), following the manufacturer's instructions. These reactions were run on an ABI Prism 7000 Sequence Detection System, running ABI 7000 System SDS Software (Applied Biosystems, Carlsbad, CA) for 40 cycles followed by a dissociation cycle, according to standard protocols. Three biological replicates were performed for every kernel position and time point.

Affymetrix GeneChip analysis. GeneChip data from previous studies on barley and wheat $(18,20)$ and in culture (21) were normalized using RMA in R and Bioconductor $(15,24,25)$, as described by Hallen et al. (21). Wheat inoculations in the previous study (18) were done similarly to those described here. Barley inoculations were accomplished by spraying heads with a spore suspension (20). The genes involved in the trichothecene biosynthetic pathway, along with three housekeeping genes (GAPDH, $E F 1 A$, and $\beta$-tubulin [FGSG_09530]) were used to generate a heat map using heatmap.2, part of the gplots package in $\mathrm{R}$ (http://cran.r-project.org/web/packages/gplots/index.html).

DON quantification. DON measurements were taken for a subset of kernels intended to represent different stages of infection. One kernel per rachis node was set aside for DON quantification by gas chromatography (GC), while the other kernel was used for qRT-PCR. Each kernel was weighed, extracted, and quantified separately. Kernels were ground in liquid nitrogen and DON was extracted overnight at room temperature in an orbital shaker at $180 \mathrm{rpm}$ with $10 \mathrm{ml}$ of high-performance liquid chromatography-grade acetonitrile/water $(84: 16)$ per kernel. Samples were centrifuged at $2,400 \mathrm{rpm}$ at $21^{\circ} \mathrm{C}$ for $10 \mathrm{~min}$, and the supernatant was collected. From each sample, $4 \mathrm{ml}$ was eluted through a column packed with $0.5 \mathrm{~g}$ of a mixture consisting of $28 \mathrm{~g}$ of Darco G-60 charcoal, $20.1 \mathrm{~g}$ of aluminum oxide, and $1 \mathrm{~g}$ of celite 545 , and followed by an additional $1 \mathrm{ml}$ of acteonitrile/ water (84:16). Cleaned extracts were evaporated to dryness overnight under warm nitrogen. Evaporated samples were prepared for analysis by dissolving in $100 \mu$ of 4-dimethylaminopyridine (2 $\mathrm{mg} \mathrm{ml}^{-1}$, in toluene; Mirex at $1 \mu \mathrm{g} \mathrm{ml} \mathrm{m}^{-1}$ [Chem Service, 
Westchester, PA] was used as an internal standard), and $50 \mu \mathrm{l}$ of heptafluorobutyric acid (Campbell Scientific, Logan, UT) was added as a derivitizing agent. Samples were mixed well and incubated at $65^{\circ} \mathrm{C}$ for $1 \mathrm{~h}$. The reaction was neutralized with $1 \mathrm{ml}$ of $3 \%$ sodium bicarbonate and further diluted with $150 \mu \mathrm{l}$ of toluene. The toluene-based portion of the sample was decanted into an autosampler vial for analysis. Each sample $(1 \mu \mathrm{l})$ was injected onto a Shimadzu GC-17A model gas chromatograph (Shimadzu Scientific, Columbia, MD). The separation and detection system consisted of an Rtx-5 Crossbond column (15 m, 0.25-mm i.d., 0.25- $\mu \mathrm{m}$ df) (Restek Corporation, Bellefonte, PA) with a $5-\mathrm{m}$ guard and an ECD ${ }^{63} \mathrm{Ni}$ detector. Samples were run alternately with DON-spiked wheat standards as calibration controls. A split injection was used, with a ratio of 1:25. The carrier gas was ultrapure helium at a flow rate of $1.3 \mathrm{ml} \mathrm{min}^{-1}$, while zero-grade nitrogen was used for the make-up gas. The injector was set at $300^{\circ} \mathrm{C}$ and detector temperature was $310^{\circ} \mathrm{C}$. Oven temperature was initially $80^{\circ} \mathrm{C}$ and increased by $65^{\circ} \mathrm{C} \mathrm{min} \mathrm{m}^{-1}$ to $171^{\circ} \mathrm{C}, 1.2^{\circ} \mathrm{C} \mathrm{min}^{-1}$ to $182^{\circ} \mathrm{C}, 45^{\circ} \mathrm{C} \mathrm{min}^{-1}$ to $228^{\circ} \mathrm{C}$, and $0.1^{\circ} \mathrm{C} \mathrm{min}{ }^{-1}$ to $229^{\circ} \mathrm{C}\left(182^{\circ} \mathrm{C}\right.$ was used to detect DON and $229^{\circ} \mathrm{C}$ was used to detect the internal standard, Mirex). DON was quantified by comparison with a standard curve of DON analytical standard (Biopure) obtained from Romer Labs (Union, MO). DON quantities (ppm) were averaged across eight kernels for any given treatment.

\section{RESULTS}

GeneChip analyses. A heat map showing expression of DON biosynthetic genes and some representative housekeeping genes during an in vitro developmental time course on carrot agar, and during barley infection and wheat stem colonization, is given in Figure 1. DON biosynthetic genes were expressed predominantly in planta, with the earliest expression detected at $48 \mathrm{~h}$ postinoculation in barley. In wheat stems, DON biosynthetic gene expression was detected in the infection front and just behind the infection front in the "water-soaked" zone but not in senescent wheat. Housekeeping genes EFIA and GAPDH were highly expressed throughout.

Course of visible infection. Infection was visible at the inoculated kernel upon removal from the mist chamber (3 dpi); the developing kernel (watery ripe; Zadoks 71) was shriveled and discolored. Rarely, white-to-pink mycelial growth was visible on the kernel or glume. No macroscopically visible damage was detected on any other kernel at $4 \mathrm{dpi}$, including the kernel adjacent to the IP. For susceptible Wheaten, macroscopically visible symptoms (beyond the IP) first evinced at $8 \mathrm{dpi}$, both above and below the IP. Symptoms progressed outward from the IP, with some infection detectable at all kernel positions by 14 dpi (Fig. 2 ). We did not differentiate between different types of fungalinduced damage to the wheat kernel, which included water soaking, discoloration, shriveling, drying (distinct from the loss of moisture that occurs naturally during maturation), and the presence of superficial mycelia. Bleaching of the glumes and a bending and distortion of the awn tracked or shortly preceded the manifestation of symptoms on the kernels.

As infection progressed in Wheaten (14 dpi and afterward), kernels above the IP became increasingly difficult to harvest. The combination of progressing fungal infection and probable diminished water transport, due to fungal hyphae infiltrating and plugging the vascular tissue, resulted in severely stunted kernels (average mass $<10 \mathrm{mg} / \mathrm{kernel}$ dry weight compared with $>20 \mathrm{mg}$ for equivalent kernels in healthy and mock-inoculated plants). Beginning at $16 \mathrm{dpi}$, the stem immediately below the wheat head had begun to exhibit water-soaking symptoms in some plants.

Wheaten plants were treated with the azoxystrobin at boot and immediately following removal from the mist chamber (shortly after anthesis and $3 \mathrm{dpi}$ ). Development of visible symptoms did not differ between fungicide-treated and untreated plants.
Spring wheat Alsen, carrying FHB1-mediated head blight resistance, exhibited minimal development of symptoms of infection. The inoculated kernel was visibly infected upon removal from the mist chamber, as was the case for Wheaten. By $14 \mathrm{dpi}$, $<20 \%$ of the kernels at the -1 and -2 position exhibited visible damage, and no other kernels were symptomatic. The greatest spread of infection observed was at $17 \mathrm{dpi}$, when kernels at +1 , $-1,-2$, and -3 showed some damage. At no point (up to $21 \mathrm{dpi}$, the last day of data collection) were $>20 \%$ of the kernels at any given position on an Alsen plant visibly infected.

qRT-PCR on Tri5 gene expression. In Wheaten, fungal nucleic acids were detected as early as $6 \mathrm{dpi}$, preceding the development of visible symptoms by 2 days. At 6 dpi, transcripts for all three fungal genes (GAPDH, EF1A, and Tri5) were detected in the kernels immediately above and below the IP (kernel positions +1 and -1 , respectively). Transcripts of the housekeeping genes $G A P D H$ and $E F I A$ were detected at kernels $+2,-2$, and -3 , whereas Tri5, the trichodiene synthase gene, was not detected in these kernels. By $13 \mathrm{dpi}$, Tri5 as well as transcripts of the representative housekeeping genes were detected in all kernels.

The highest Tri5 expression relative to GAPDH (and EF1A) expression (cycle threshold [Ct] ratio) was observed in asymptomatic tissue at the infection front (Fig. 2); Tri5 transcript levels in these kernels were as high as or slightly higher than the levels of the housekeeping genes. As infection progressed, kernels closest to the IP showed diminished Tri5 expression relative to housekeeping gene expression but Tri5 expression was not seen to cease during the 21 days observed. Kernels from mock-inoculated plants were harvested at 10 and $21 \mathrm{dpi}$ for a negative control, and no fungal gene transcripts were detected from these, whereas wheat actin transcripts were detected (data not shown).

Relative Tri5 expression in azoxystrobin-treated Wheaten did not differ significantly from that in untreated Wheaten (data not shown). Resistant Alsen showed significant deviation in Tri5 (and fungal housekeeping) gene expression in comparison with Wheaten (Fig. 2). Tri5 was never detected in kernels below -3 or above +1 , and $G A P D H$ (and $E F 1 A$ ) expression did not extend below -4 . Interestingly, for the final day of the time course, 21 dpi, no fungus was detected below -1 , although Tri5 and GAPDH expression had been detected at -2 on 11,14 , and $17 \mathrm{dpi}$, and at -3 on 17 dpi (three independent replicates, each consisting of at least 12 pooled kernels).

DON levels in kernels. DON quantities ranged from none detected (most kernels collected beyond the infection front) to 183 ppm (a single kernel of Wheaten $21 \mathrm{dpi},-8$ ). Alsen kernels exhibited negligible quantities of DON, with the highest level being $32 \mathrm{ppm}$ in a single kernel ( $8 \mathrm{dpi},-4$; average across $8 \mathrm{dpi}$, -4 Alsen kernels $=10.2 \mathrm{ppm})$. DON was not detected in significant quantities in Alsen at any kernel position in the later stages sampled $(11,14,17$, and $21 \mathrm{dpi})$. In Wheaten, DON levels were negligible at $8 \mathrm{dpi}$, with detectable DON at 11, 14, 17, and 21 dpi. DON levels for kernel position -4 declined slightly over time (from $44.6 \mathrm{ppm}$ at $11 \mathrm{dpi}$ to $28.6 \mathrm{ppm}$ at $21 \mathrm{dpi}$ ). DON levels averaged across kernels from representative positions (1, 4, and 8 nodes below the IP) are shown in Table 1. Wheaten plants treated with azoxystrobin did not differ significantly in DON levels from untreated plants. DON levels $<20 \mathrm{ppm}$ were considered not significant, because they were difficult to distinguish from background levels.

\section{DISCUSSION}

Analysis of expression data from multiple conditions in wheat and barley and in culture revealed a distinct pattern of expression for the DON biosynthetic genes. We investigated this further in both susceptible and resistant cultivars of wheat to determine the relationship of Tri5 gene expression to progress of infection. Transcription was most active at the infection front before symp- 
tom development, consistent with the role of DON in establishing infection and colonization. Interestingly, Tri5 and fungal GAPDH and EF1A transcripts remained detectable, albeit reduced, in infected tissue of the susceptible cultivar after the plant tissue had completely senesced (wheat actin transcripts no longer detectable). In the resistant cultivar, initial fungal invasion was halted and the fungus appeared to retreat by the end of the sampling. The apparent correlation between early stages of plant infection and highest levels of DON biosynthetic gene transcripts suggested the potential value of the strobilurin fungicide in dissecting the interactions between fungus and plant in Fusarium head blight. However, no significant differences were observed between sus-

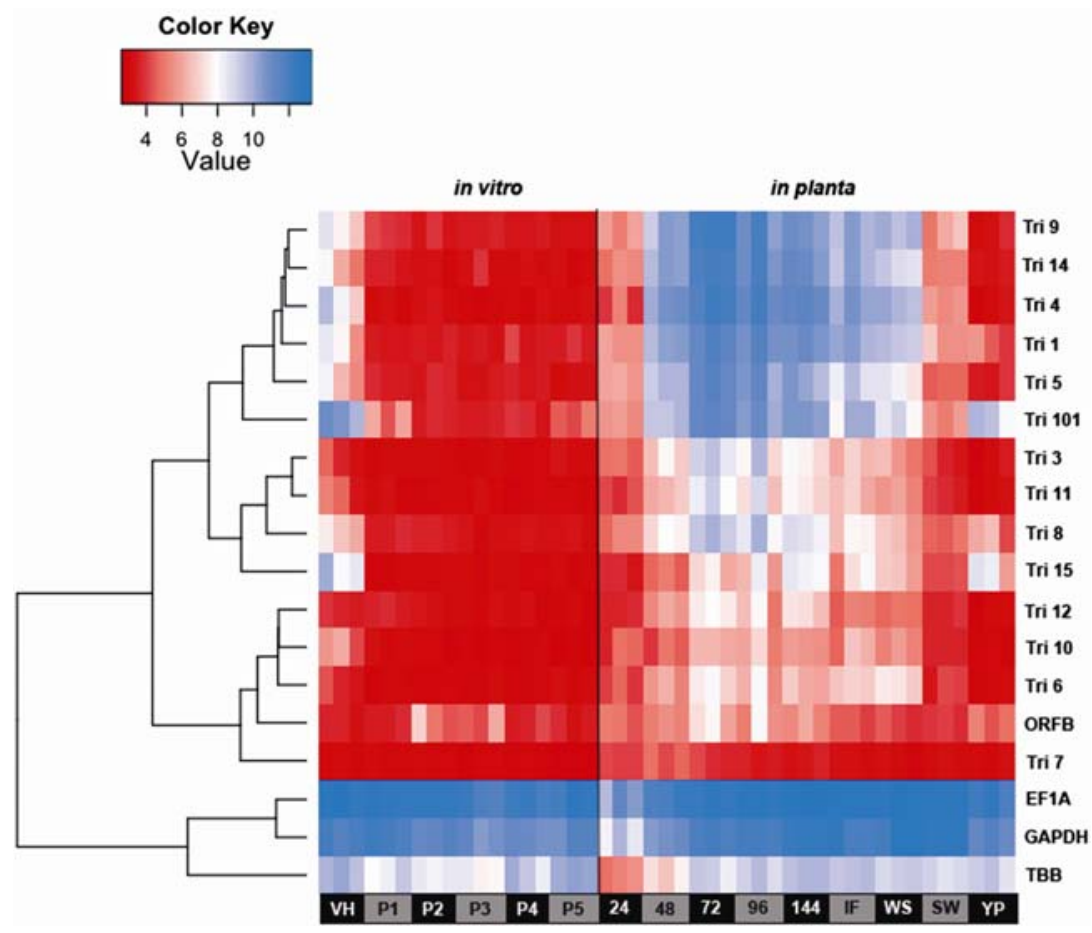

Fig. 1. Heat map of GeneChip data showing expression of trichothecene biosynthetic genes. Gene expression is given as $\log _{2}$-normalized intensity values. Housekeeping genes are included as controls: $\mathrm{EF} 1 \mathrm{~A}=$ transcription elongation factor $1 \alpha, \mathrm{GAPDH}=$ glyceraldehyde phosphate dehydrogenase, $\mathrm{TBB}=\beta$-tubulin . In vitro growth conditions: $\mathrm{VH}=$ vegetative hyphae, P1 to P5 = sequentially developing perithecia, with P1 representing the earliest perithecial initials and P5 mature perithecia with ascospores. Numerical values in planta are hours postinoculation in barley heads. Other in planta values are taken from wheat stems: IF $=$ infection front (asymptomatic); WS = water-soaking symptoms, just behind the infection front; SW = senescent, bleached wheat; and YP = young perithecia following incubation of stems in moist vermiculite.

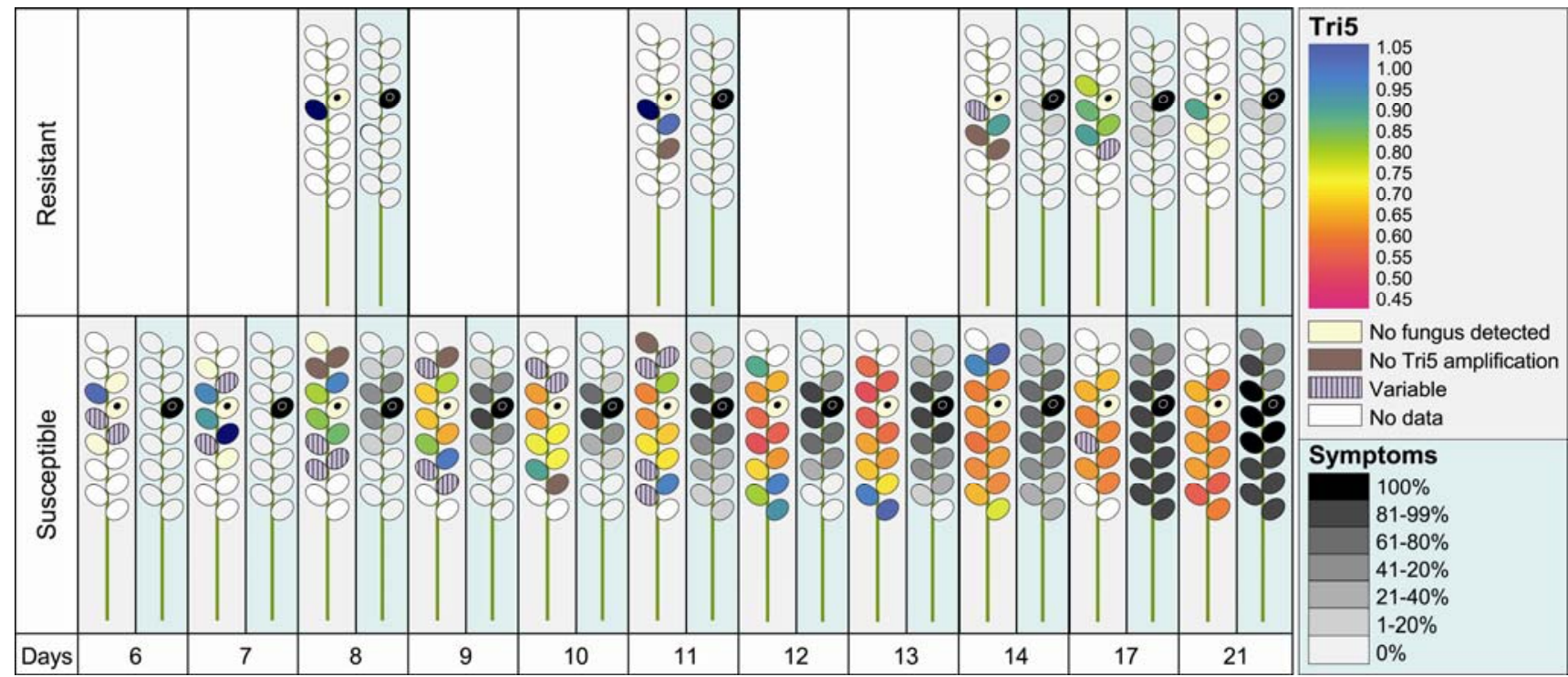

Fig. 2. Deoxynivalenol (DON) gene expression and percent kernel infection relative to inoculation point. Top row is 'Alsen' (carrying FHB1-mediated resistance) plants and bottom row is 'Wheaten' (susceptible). Numbers refer to days postinoculation. Transcript abundance of the DON biosynthetic gene Tri5 relative to the housekeeping gene glyceraldehyde phosphate dehydrogenase $(G A P D H)$, as determined by cycle threshold (Ct)Tri5/CtGAPDH, is shown in color (left); blue indicates higher proportional Tri5 transcript abundance, while red and pink indicate lower proportional abundance. GAPDH is constitutively expressed and is detected whenever the fungus is present. "Variable" kernel positions indicate that Tri5 was detected in one or more replicates, while at least one replicate lacked Tri5 or fungal gene expression. Percent kernels showing visible infection at harvest is shown in grayscale (right). Symptoms of infection included water-soaking at the point of attachment to the rachis, softening and rotting of the kernel, drying and shriveling of the kernel, and fungal hyphal growth. Inoculation point is indicated by the black spot on the middle right kernel. 
ceptible spring wheat treated with azoxystrobin and untreated plants, in either visible symptom development, DON quantities, or Tri5 (or fungal housekeeping) gene transcript abundance.

The striking increase in expression of several Tri genes (including Tri5) $72 \mathrm{~h}$ after inoculation of barley (Fig. 1) corresponds to the first appearance of lesions (4), when the fungus is just becoming abundant in the plant. The peak of expression of Tri5 in the present study in wheat appears consistently at the infection front. In wheat, Tri5 expression of invading hyphae was shown to be moderated by tissues in the head, with kernel tissue having strong inductive effects (23). Our results suggest that the inductive effect lessens as the kernel is increasingly colonized (Fig. 2). Regulation of the Tri pathway is complex, with positive and negative regulatory factors at play $(12,40)$, as well as nutritional sources (27) and $\mathrm{pH}(32)$.

qRT-PCR studies reflect the relative transcript level of the genes of interest - in this case, Tri5 - and not merely presence of genes that may or may not be expressed under study conditions. Schmidt-Heydt and colleagues (39) used the expression levels of six genes in the trichothecene pathway (Tri4, Tri5, Tri6, Tri10, Tri12, and Tri13) to derive a polynomial equation linking DON levels to gene expression in F. graminearum and F. culmorum, with an $R^{2}$ of 0.9542 . Our study primarily examined expression of Tri5 relative to fungal housekeeping genes, which yields results inconsistent with quantitative DON prediction. For example, in susceptible Wheaten, the highest DON level observed (158 ppm) was associated with a comparatively low $\mathrm{Ct}$ ratio (0.6), whereas higher $\mathrm{Ct}$ ratios-and, thus, higher relative Tri5 expression-correlated with much lower DON levels (22 to $45 \mathrm{ppm}$ ). This is explicable by the fact that the highest relative Tri5 expression was consistently observed at or near the infection front, where overall gene expression of both Tri5 and housekeeping genes GAPDH and EF1A was comparatively low, due to the reduced presence of the fungus.

Several qPCR studies have used the presence and quantification of Tri5 in genomic DNA as a marker for the presence of potentially trichothecene-producing Fusarium spp. $(22,38,47)$. By providing a quantitative measure of Fusarium spp. present in the host plant, this qPCR data can be correlated with disease severity or, conversely, with grain yield and quality (22). Zhang and colleagues (47) reported a significant linear relationship between $\log _{10}$ Tri5 DNA and DON quantity; however, arguably, their use

TABLE 1. Relative expression of Tri5 and deoxynivalenol (DON) accumulation (ppm) in representative kernels of susceptible and resistant wheat cultivars

\begin{tabular}{|c|c|c|c|}
\hline $\begin{array}{l}\text { Wheat, dpi, } \\
\text { position }^{\text {a }}\end{array}$ & $\begin{array}{l}\text { Tri5 expression } \\
\text { (standard error) }^{\mathrm{b}}\end{array}$ & $\begin{array}{l}\text { Kernels infected } \\
\qquad(\%)\end{array}$ & $\begin{array}{c}\text { DON (ppm) } \\
\text { (standard error) }\end{array}$ \\
\hline W8, -4 & ND & 0 & 2.03 (1.19) \\
\hline $\mathrm{W} 11,-4$ & $0.75(0.07)$ & 34 & $44.60(10.83)$ \\
\hline W17, -4 & $0.62(0.05)$ & 96 & $36.50(12.70)$ \\
\hline W21, -4 & $0.62(0.05)$ & 96 & $28.60(4.95)$ \\
\hline $\mathrm{W} 11,-8$ & $\mathrm{NM}$ & 11 & $3.43(1.60)$ \\
\hline $\mathrm{W} 14,-8$ & $0.78(0.04)$ & 25 & $21.90(2.84)$ \\
\hline $\mathrm{W} 21,-8$ & $0.60(0.002)$ & 91 & $158.00(10.16)$ \\
\hline A14, -1 & $0.68 ; \mathrm{IF}$ & 7 & $0.88(0.58)$ \\
\hline A $17,-1$ & $0.86(0)$ & 19 & $1.77(0.63)$ \\
\hline A $21,-1$ & $0.86(0.01)$ & 9 & $1.04(0.74)$ \\
\hline A8, -4 & NM & 0 & $10.20(4.14)$ \\
\hline $\mathrm{A} 14,-4$ & ND & 0 & $0.88(0.54)$ \\
\hline A $17,-4$ & ND & 0 & $2.05(1.48)$ \\
\hline A $21,-4$ & ND & 0 & $2.50(1.25)$ \\
\hline
\end{tabular}

a $\mathrm{W}=$ susceptible 'Wheaten', and $\mathrm{A}=$ resistant 'Alsen' at days postinoculation (dpi) for each kernel position.

b ND = Tri5 was not detected, NM = no measurement taken, and IF = infection front; one or more reps showed no detectable fungus, while one or more reps detected housekeeping genes and, in some cases, Tri5. Data from the rest of the head suggests no Tri5 for W11, -8 , and no fungus for the Alsen NMs. DON values <20 could not be reliably distinguished from background. of genomic DNA as a template suggests that the same relationship may have been observed had they used any single-copy Fusarium gene as their marker.

The resistant spring wheat Alsen exhibited minimal symptom development over 21 days; at the worst, kernels from immediately above to three below the IP were affected, and $<20 \%$ of kernels at any given position showed damage. The 21-dpi plants exhibited a reduction in Tri5 transcripts and fungal housekeeping gene transcripts compared with 17 and 14 dpi plants. The FHB1 resistance carried by Alsen is correlated with a resistance to DON accumulation, although the mechanism is not known. Our data show that relative expression of Tri5 can be quite high in Alsen compared with Wheaten (Fig 2; Table 1) even relatively late in the infection, at day 17. This implies that the resistance mechanism may affect mycelial spread rather than transcription of DON biosynthetic genes. Investigations are in progress to further understand this observation and determine its significance for resistance.

The infection results for Wheaten clearly show that the infection spreads out from the IP both upward and downward. Previous work has shown that the infection front is mainly colonization of the xylem $(19,26)$. By the time the infection reached the bottom of the head (12 dpi), the upper florets were severely shriveled, due to plugging of the vascular system, and the fungus stopped colonizing. The infection front continued past the lowest floret and began to move down the stem.

A major concern for wheat contamination is the presence of asymptomatic grain that has significant toxin levels. These grains are hard to eliminate, because they cannot be physically recognized and there is little understanding of how these infections develop. Other workers have shown that more mature kernels can become infected and show few symptoms but harbor significant DON levels $(6,8)$. The present studies suggest that the highest DON may be associated with early infection. The data presented here show that genes for DON synthesis can be relatively highly expressed in very little mycelium, before symptoms develop. Furthermore, transcripts for DON biosynthetic genes remain even after host tissue senesces. This suggests that infections which, due to environmental or host conditions, remain small may have the potential to produce large amounts of DON in a small amount of mycelium, should environmental conditions permit. Further investigations will be geared toward understanding this interaction.

\section{ACKNOWLEDGMENTS}

This material is based upon work supported by the United States Department of Agriculture (USDA), under Agreement No. 59-0790-6-068 with F. Trail. This is a cooperative project with the U.S. Wheat \& Barley Scab Initiative. Any opinions, findings, conclusions, or recommendations expressed in this publication are those of the author(s) and do not necessarily reflect the view of the USDA. We thank M. Cameron for assistance with Figure 2, W. Kirk for suggestions on the fungicide experiments, and R. Schafer for assistance with fungicide applications.

\section{LITERATURE CITED}

1. Adams, G. C., and Hart, L. P. 1989. The role of deoxynivalenol and 15acetyldeoxynivalenol in pathogenesis by Gibberella zeae, as elucidated through protoplast fusions between toxigenic and nontoxigenic strains. Phytopathology 79:404-408.

2. Bai, G. H., Desjardins, A. E., and Plattner, R. D. 2001. Deoxynivalenolnonproducing Fusarium graminearum causes initial infection but does not cause disease spread in wheat spikes. Mycopathologia 153:91-98.

3. Bertelsen, J. R., de Neergaard, E., and Smedagaard-Petersen, V. 2001. Fungicidal effects of azoxystrobin and epoxiconazole on phyllosphere fungi, senescence and yield of winter wheat. Plant Pathol. 50:190-205.

4. Bushnell, W. R., Hazen, B. E., and Pritsch, C. 2003. Histology and physiology of Fusarium head blight. Pages 44-83 in: Fusarium Head Blight of Wheat and Barley. K. J. Leonarda and W. R. Bushnell, eds. The American Phytopathological Society, St. Paul, MN.

5. Chala A., Weinert, J., and Wolf, G. A. 2003. An integrated approach to the evaluation of the efficacy of fungicides against Fusarium culmorum, the 
cause of head blight of wheat. J. Phytopathol. 151:673-678.

6. Cowger, C., and Arrellano, C. 2010. Plump kernels with high deoxynivalenol linked to late Gibberella zeae infection and marginal disease conditions in winter wheat. Phytopathology 100:719-728.

7. Cuomo, C. A., Güldener, U., Xu, J.-R., Trail, F., Turgeon, B. G., Di Pietr, A., Walton, J. D., Ma, L.-J., Baker, S. E., Rep, M., Adam, G., Antoniw, J., Baldwin, T., Calvo, S., Chang, Y.-L., DeCaprio, D., Gale, L., R., Gnerre, S., Goswami, R. S., Hammond-Kosack, K., Harris, L. J., Hilburn, K., Kennel, J. C., Kroken, S., Magnuson, J. K., Mannhaupt, G., Mauceli, E., Mewes, H.-W., Mitterbauer, R., Muehlbauer, G., Münsterkötter, M., Nelson, D., O’Donnell, K., Ouellet, T., Qi, W., Quesneville, H., Roncero, M. I. G., Seong, K.-Y., Tetko, I. V., Urban, M., Waalwijk, C., Ward, T. J., Yao, J., Birren, B. W., and Kistler, H. C. 2007. The Fusarium graminearum genome reveals a link between localized polymorphism and pathogen speciation. Science 317:1400-1402.

8. Del Ponte, E. M., Fernandes, J. M. C., and Bergstrom, G. C. 2007. Influence of growth stage on Fusarium head blight and deoxynivalenol production in wheat. J. Phytopathol. 155:577-581.

9. Desjardins, A. E. 2006. Fusarium Mycotoxins-Chemistry, Genetics, and Biology. American Phytopathological Society, St. Paul, MN.

10. Desjardins, A. E., Proctor, R. H., Bai, G. H., McCormick, S. P., Buechley, G., and Hohn, T. M. 1996. Reduced virulence of trichothecenenonproducing mutants of Gibberella zeae in wheat field tests. Mol. PlantMicrobe Interact. 9:775-781.

11. Gaffoor, I., and Trail, F. 2006. Characterization of two polyketide synthase genes involved in zearalenone biosynthesis in Gibberella zeae. Appl. Environ. Microbiol. 72:1793-1799.

12. Gardiner, D. M., Kazan, K., and Manners, J. M. 2009. Novel genes of Fusarium graminearum that negatively regulate deoxynivalenol production and virulence. Mol. Plant-Microbe Interact. 22:1588-1600.

13. Gardiner, D. M., Kazan, K., and Manners, J. M. 2009. Nutrient profiling reveals potent inducers of trichothecene biosynthesis in Fusarium graminearum. Fungal Genet. Biol. 46:604-613.

14. Gardiner, D. M., Kazan, K., Praud, S., Torney, F. J., Rusu, A., and Manners, J. M. 2010. Early activation of wheat polyamine biosynthesis during Fusarium head blight implicates putrescine as an inducer of trichothecene mycotoxin production. BMC Plant Biol. 10:289.

15. Gentleman, R. C., Carey, V. J., Bates, D. M., Bolstad, B., Dettling, M., Dudoit, S., Ellis, B., Gautier, L., Ge, Y., Gentry, J., Hornik, K., Hothorn, T., Huber, W., Iacus, S., Irizarry, R., Leisch, F., Li, C., Maechler, M., Rossini, A. J., Sawitzki, G., Smith, C., Smyth, G., Tierney, L., Yang, J. Y. J., and Zhang, J. 2004. Bioconductor: open software development for computational biology and bioinformatics. Genome Biol. 5:R80.

16. Goswami, R. S., and Kistler, H. C. 2005. Pathogenicity and in planta mycotoxin accumulation among members of the Fusarium graminearum species complex on wheat and rice. Phytopathology 95:1397-1404.

17. Goswami, R. S., Xu, J. R., Trail, F., Hilburn, K., and Kistler, H. C. 2006. Genomic analysis of host-pathogen interaction between Fusarium graminearum and wheat during early stages of disease development. Microbiology 152:1877-1890.

18. Guenther, J. C., Hallen-Adams, H. E., Bücking, H., Shachar-Hill, Y., and Trail, F. 2009. Triacylglyceride metabolism by Fusarium graminearum during colonization and sexual development on wheat. Mol. PlantMicrobe Interact. 22:1492-1503.

19. Guenther, J. C., and Trail, F. 2005. The development and differentiation of Gibberella zeae (anamorph: Fusarium graminearum) during colonization of wheat. Mycologia 97:229-237.

20. Güldener, U., Seong, K. Y., Boddu, J., Cho, S., Trail, F., Xu, J. R., Adam, G., Mewes, H. W., Muehlbauer, G. J., and Kistler, H. C. 2006. Development of a Fusarium graminearum Affymetrix GeneChip for profiling fungal gene expression in vitro and in planta. Fungal Genet. Biol. 43:316-325.

21. Hallen, H. E., Huebner, M., Shiu, S.-H., Güldener, U., and Trail, F. 2007. Gene expression shifts during perithecium development in Gibberella zeae (anamorph Fusarium graminearum), with particular emphasis on ion transport proteins. Fungal Genet. Biol. 44:1146-1156.

22. Hogg, A. C., Johnston, R. H., and Dyer, A. T. 2007. Applying real-time quantitative PCR to Fusarium crown rot of wheat. Plant Dis. 91:1021-1028.

23. Ilgen, P., Hadeler, B., Maier, F. J., and Schafer, W. 2009. Developing kernel and rachis node induce the trichothecene pathway of Fusarium graminearum during wheat head infection. Mol. Plant-Microbe Interact. 22:899-908.

24. Irizarry, R. A., Bolstad, B. M., Collin, F., Cope, L. M., Hobbs, B., and Speed, T. P. 2003. Summaries of Affymetrix GeneChip probe level data. Nucleic Acids Res. 31:Art. No. e15.

25. Irizarry, R. A., Hobbs, B., Collin, F., Beazer-Barclay, Y. D., Antonellis, K. J., Scherf, U., and Speed, T. P. 2003. Exploration, normalization, and summaries of high density oligonucleotide probe level data. Biostatistics 4:249-264.

26. Jansen, C., von Wettstein, D., Schäfer, W., Kogel, K.-H., Felk, A., and Maier, F. J. 2005. Infection patterns in barley and wheat spikes inoculated with wild-type and trichodiene synthase gene disrupted Fusarium graminearum. Proc. Natl. Acad. Sci. USA 102:16892-16897.

27. Jiao, F., Kawakami, A., and Nakajima, T. 2008. Effects of different carbon sources on trichothecene production and Tri gene expression by Fusarium graminearum in liquid culture. FEMS Microbiol. Lett. 285:212-219.

28. Lee, J., Jurgenson, J. E., Leslie, J. F., and Bowden, R. L. 2008. Alignment of genetic and physical maps of Gibberella zeae. Appl. Environ. Microbiol. 74:2349-2359.

29. Lee, T., Han, Y. K., Kim, K. H., Yun, S. H., and Lee, Y. W. 2002. Tri13 and $\mathrm{Tri} 7$ determine deoxynivalenol- and nivalenol-producing chemotypes of Gibberella zeae. Appl. Environ. Microbiol. 68:2148-2154.

30. Maier, F. J., Miedaner, T., Hadeler, B., Felk, A., Salomon, S., Lemmens, M., Kassner, H., and Schäfer, W. 2006. Involvement of trichothecenes in fusarioses of wheat, barley and maize evaluated by gene disruption of the trichothecene synthase (Tri5) gene in three field isolates of different chemotype and virulence. Mol. Plant Pathol. 7:449-461.

31. McCormick, S. P., Harris, L. J., Alexander, N. J., Ouellet, T., Saparno, A., Allard, S., and Desjardins, A. E. 2004. Tri1 in Fusarium graminearum encodes a P450 oxygenase. Appl. Environ. Microbiol. 70:2044-2051.

32. Merhej, J., Richard-Forget, F., and Barreau, C. 2011. The pH regulatory factor Pac1 regulates Tri gene expression and trichothecene production in Fusarium graminearum. Fungal Genet. Biol. 48:275-284.

33. Mudge, A. M., Dill-Macky, R., Dong, Y., Gardiner, D. M., White, R. G., and Manners, J. M. 2006. A role for the mycotoxin deoxynivalenol in stem colonization during crown rot disease of wheat caused by Fusarium graminearum and Fusarium pseudograminearum. Physiol. Mol. Plant Pathol. 69:73-85.

34. Niessen, L. 2007. PCR-based diagnosis and quantification of mycotoxin producing fungi. Int. J. Food Microbiol. 119:38-46.

35. Pirgozliev, S. R., Ray, R. V., Edwards, S. G., Hare, M. C., and Jenkinson, P. 2008. Effect of timing of fungicide application on the development of Fusarium head blight and the accumulation of deoxynivalenol (DON) in winter wheat grain. Cereal Res. Commun. 36:289-299.

36. Proctor, R. H., Hohn, T. M., and McCormick, S. P. 2005. Reduced virulence of Gibberella zeae caused by disruption of a trichothecene toxin biosynthetic gene. Mol. Plant-Microbe Interact. 8:593-601.

37. Proctor, R. H., McCormick, S. P., Alexander, N. J., and Desjardins, A. E. 2009. Evidence that a secondary metabolic biosynthetic gene cluster has grown by gene relocation during evolution of the filamentous fungus Fusarium. Mol. Microbiol. 74:1128-1142.

38. Rossi, V., Terzi, V., Moggi, F., Morcia, C., Faccioli, P., Haidukowski, M., and Pascale M. 2007. Assessment of Fusarium infection in wheat heads using a quantitative polymerase chain reaction (qPCR) assay. Food Addit. Contam. 24:1121-1130.

39. Schmidt-Heydt, M., Parra, R., Geisen, R., and Magan, N. 2011. Modelling the relationship between environmental factors, transcriptional genes and deoxynivalenol mycotoxin production by strains of two Fusarium species. J. R. Soc. Interface 8:117-126.

40. Seong, K.-Y., Pasquall, M., Zhou, X., Song, J., Hilburn, K., McCormick, S., Dong, Y., Xu, J.-R., and Kistler, H. C. 2009. Global gene regulation by Fusarium transcription factors Tri6 and Tri10 reveals adaptations for toxin biosynthesis. Mol. Microbiol. 72:354-367.

41. Stephens, A. E., Gardiner, D. M., White, R. G., Munn, A. L., and Manners, J. M. 2008. Phases of infection and gene expression of Fusarium graminearum during crown rot disease of wheat. Mol. Plant-Microbe Interact. 21:1571-1581.

42. Trail, F. 2009. For blighted waves of grain: Fusarium graminearum in the post-genomics era. Plant Physiol. 149:103-110.

43. Trail, F., and Common, R. 2000. Perithecium development in Gibberella zeae, a light microscopy study. Mycologia 92:130-138.

44. Voigt, C. A., von Scheidt, B., Gácser, A., Kassner, H., Lieberei, R., Schäfer, W., and Salomon, S. 2007. Enhanced mycotoxin production of a lipase-deficient Fusarium graminearum mutant correlates to toxin-related gene expression. Eur. J. Plant Pathol. 117:1-12.

45. Walter, S., Brennan, J. M., Arunachalam, C., Ansari, K. I., Hu, X., Khan, M. R., Trognitz, F., Trognitz, B., Leonard, G., Egan, D., and Doohan, F. M. 2008. Components of the gene network associated with genotypedependent response of wheat to the Fusarium mycotoxin deoxynivalenol. Funct. Integr. Genomics 8:421-427.

46. Zadoks, J. C., Chang, T. T., and Konzak, C. F. 1974. A decimal code for the growth stages of cereals. Weed Res. 14:415-421.

47. Zhang, Y. J., Fan, P. S., Zhang, X., Chen, C. J., and Zhou, M. G. 2009. Quantification of Fusarium graminearum in harvested grain by real-time polymerase chain reaction to assess efficacies of fungicides on Fusarium head blight, deoxynivalenol contamination, and yield of winter wheat. Phytopathology 99:95-100.

48. Zhang, Y. J., Yu, J. J., Zhang, Y. N., Zhang, X., Cheng, C. J., Wang, J. X., Hollomon, D. W., Fan, P. S., and Zhou, M. G. 2009. Effect of carbendazim resistance on trichothecene production and aggressiveness of Fusarium graminearum. Mol. Plant-Microbe Interact. 22:1143-1150. 